\title{
Postconflict Behaviour in Brown Capuchin Monkeys (Cebus apella)
}

\author{
João R. Daniel António J. Santos Mónica G. Cruz \\ Instituto Superior de Psicologia Aplicada, Unidade de Investigação em Psicologia \\ Cognitiva do Desenvolvimento e da Educação, Lisboa, Portugal
}

\section{Key Words}

Agonistic interactions $\cdot$ Cebus apella $\cdot$ Multivariate analysis $•$ Postconflict anxiety • Reconciliation $\cdot$ Relationship quality

\begin{abstract}
Postconflict affiliation has been mostly studied in Old World primates, and we still lack comparative research to understand completely the functional value of reconciliation. Cebus species display great variability in social characteristics, thereby providing a great opportunity for comparative studies. We recorded 190 agonistic interactions and subsequent postconflict behaviour in a captive group of brown capuchin monkeys (Cebus apella). Only $26.8 \%$ of these conflicts were reconciled. Reconciliation was more likely to occur between opponents that supported each other more frequently and that spent more time together. Postconflict anxiety was mostly determined by conflict intensity, and none of the variables thought to measure relationship quality had a significant effect on postconflict stress.

Copyright @ 2009 S. Karger AG, Basel
\end{abstract}

\section{Introduction}

Recent comparative analyses within the genus Macaca have revealed that closely related primate species often differ strikingly in suites of social traits that may cohere for functional and/or phylogenetic reasons [Thierry et al., 2008]. Reconciliation, or 'the postconflict friendly reunion of former opponents' [Aureli and de Waal, 2000], is thought to play a key role in repairing and maintaining social relationships. Thus, it is unsurprising that the frequency and form of reconciliation is linked across species to other social traits (e.g. kin bias, levels of counteraggression).

It is important to extend such comparative analyses to other genera. Cebus contains 5 species (or 8 according to recent classifications, as in Rylands et al. [2000] and

\begin{tabular}{|c|c|}
\hline RGER & $\begin{array}{l}\text { (c) } 2009 \text { S. Karger AG, Basel } \\
0015-5713 / 09 / 0805-0329 \$ 26.00 / 0\end{array}$ \\
\hline $\begin{array}{l}\text { Fax +41 } 613061234 \\
\text { E-Mail karger@karger.ch } \\
\text { www.karger.com }\end{array}$ & $\begin{array}{l}\text { Accessible online at: } \\
\text { www.karger.com/fpr }\end{array}$ \\
\hline
\end{tabular}

João Rodrigo Daniel

Instituto Superior de Psicologia Aplicada

Rua Jardim do Tabaco, 34, PT-1149-041 Lisboa (Portugal)

Tel. +351 218811700 , ext. 265

E-Mail joaordaniel@gmail.com 
Groves [2001]), with complex social lives, which differ in such social traits as number of reproductive males, occurrence of infanticide and degree of despotism [Fragaszy et al., 2004]. Thus, Cebus, like Macaca, provides an opportunity to assess the role of conciliatory tendency in overall social organization.

Cebus reconciliation studies have been conducted on white-faced capuchins (Cebus capucinus) and brown capuchin monkeys (Cebus apella). Leca et al. [2002] could not demonstrate reconciliation at the group level in white-faced capuchins, even though reconciliation occurred in kin and non-kin male/female dyads. Also for white-faced capuchins, Manson et al. [2005] found evidence of reconciliation in 1 of their 2 study periods, although their data were insufficient for a formal test of differences in conciliatory tendency. The study of Verbeek and de Waal [1997] on brown capuchins revealed the occurrence of reconciliation, but only following fights that occurred in the absence of highly attractive food. Besides the context in which conflicts occurred (presence or absence of clumped food), no other variables were related to reconciliation.

The quality of the relationship has been shown to be one of the most important determinants of reconciliation (valuable relationship hypothesis [de Waal and Aureli, 1997]). Relationship quality can be broken down into at least 3 dimensions: value, compatibility and security, all likely to influence reconciliation rates [Cords and Aureli, 2000]. Value refers to fitness benefits gained from the relationship (which do not need to be equal for both partners). Compatibility is a measure of the tolerance and affiliation between partners. Security refers to the predictability of the relationship. Both value and compatibility have been shown to be positively associated with the likelihood of reconciliation [Cords and Aureli, 2000; Aureli et al., 2002; Watts, 2006; Arnold and Aureli, 2007], although many of the studies where associations were found are based on the assumption that broad categories, such as kinship or age-sex combinations, index different dimensions of relationship quality [Fraser et al., 2008]. Few studies on conflict resolution focus on more than a couple of measures of relationship, and the difficulties in reliably assessing relationship security have meant that even fewer have investigated all 3 components [Cords and Aureli, 2000; Aureli et al., 2002; Watts, 2006; Arnold and Aureli, 2007; Fraser et al., 2008; Majolo et al., 2009].

On a different level, reconciliation has been shown to reduce postconflict anxiety [Aureli et al., 1989; Aureli and van Schaik, 1991; Aureli, 1992; Castles and Whiten, 1998; Das et al., 1998; Kutsukake and Castles, 2001; Cooper et al., 2007; Romero et al., 2009]. The uncertainty reduction hypothesis [Aureli et al., 1989; Aureli and van Schaik, 1991] predicts that self-directed behaviours (SDBs) should decrease after reconciliation since the uncertainty about the status of the relationship of former opponents also decreases. SDBs are good behavioural indicators of anxiety in primates [Maestripieri et al., 1992]. The valuable relationship hypothesis and the uncertainty reduction hypothesis have been integrated by Aureli [1997], suggesting that higher levels of anxiety are expected after conflicts between valuable partners.

Postconflict anxiety in brown capuchins has been studied in only immature individuals, as part of research on the impact of mother-infant relationships in the development of reconciliation [Weaver and de Waal, 2003]. The evidence indicated that at least some of the youngsters became aroused after conflicts with unrelated adults. For white-faced capuchins, postconflict rates of SDBs apparently do not differ from baseline levels [Manson and Perry, 2000]. 
Our aim with this study is to: (1) extend previous results on brown capuchins, using multivariate analysis to determine the relative importance of social variables (related to the quality of the relationship between opponents) and non-social variables (related to characteristics of the conflict or of the opponents) on the occurrence of reconciliation, and (2) illustrate the time course of postconflict anxiety, investigating factors that may affect its expression.

\section{Methods}

\section{Subjects and Housing}

Subjects were members of a captive group of brown capuchin monkeys housed at Parque Zoológico de Lagos, Portugal, in a set of outdoor islands. The group composition varied from 10 males ( 6 adults $>6$ years old, 2 immatures, 2 infants) and 5 females ( 4 adults $>5$ years old and 1 immature) in the 2004 sample period, to 12 males (6 adults, 4 immatures and 2 infants) and 4 females ( 3 adults and 1 immature) in the 2005 sample period. Mother-offspring relations were known for infant males only. Infants ( $<12$ months) were excluded from the study.

Recent classification of the genus Cebus [Rylands et al., 2000; Groves, 2001] has split C. apella into 4 species (C. apella, C. libidinosus, C. xanthosternos and C. nigritus). Given that the geographical origins of the colony founders are unknown and the morphological characters distinguishing the species are not yet clear-cut, we followed the general habit of assigning captive brown capuchins to the species C. apella [Schino et al., 2009a, b].

\section{Data Collection}

M.G.C. collected all data, from June to December 2004 and from June to November 2005.

Postconflict focal observations (PCs), of the initial recipient of aggression (hereafter victim), began as soon as an aggressive conflict ended and lasted for $10 \mathrm{~min}$ [de Waal and Yoshihara, 1983]. Aggressive conflict was defined as any interaction involving (a) threats, such as bared-teeth stare, forward thrust, head bob and piloerection, or (b) physical aggression, such as chase/pursuit, wrestle, lunge, arm swing, bite and grab [Verbeek and de Waal, 1997]. If the opponents exchanged further aggression within the first $60 \mathrm{~s}$ from the start of the PC, the observation was re-started. During PCs, all SDBs and social interactions were recorded. SDBs were recorded as the frequency of self-scratching, self-grooming and body-shaking [Schino et al., 1988]. Social interactions included affiliative (sitting in close proximity $<0.5 \mathrm{~m}$, contact-sit, grooming, affiliative signals, social play and sexual behaviour) and the aggressive behaviours described above [Izar, 1994; Verbeek and de Waal, 1997].

We conducted a matched-control observation (MC) on the same animal, at the same time on the next possible day, using the same sampling procedure. If the focal individual had been involved in an aggressive conflict within 15 min before the planned MC, or was already interacting with the former opponent at the onset of the MC, the observation was postponed for up to a maximum of $30 \mathrm{~min}$. MCs started only when the interopponent distance was similar $(0-5 \mathrm{~m}$ or $>5 \mathrm{~m})$ and the feeding context was the same as that of the matched PC. If these conditions were not met within 1 week, the PC was discarded.

We also recorded data on grooming interactions and spatial association. Grooming data were obtained by 10 -min focal samples in 2004 (mean $\pm \mathrm{SD}=8.76 \pm 0.33 \mathrm{~h} /$ individual) and 60 -min focal samples in 2005 ( $9.21 \pm 0.89 \mathrm{~h} /$ individual). We independently took an additional $173.69 \pm 1.11$ focal samples/subject in 2004 and $79.43 \pm 0.65$ in 2005, lasting $30 \mathrm{~s}$, to record the identity of each focal individual's proximity neighbours $(<1 \mathrm{~m})$, at the end of the 30 -second interval.

\section{Data Analysis}

PC-MC pairs recorded $(n=190)$ were labelled 'attracted' (i.e. pairs in which affiliative contacts occurred in a minute earlier in the PC than in the corresponding MC, or only in the PC), 'dispersed' (i.e. affiliative contacts occurring earlier in the MC than in the PC, or only in 
the MC) or 'neutral' (i.e. affiliative interactions occurring in the same minute in the PC and the MC, or not occurring at all [de Waal and Yoshihara, 1983]). Corrected conciliatory tendency (CCT) was calculated for the pooled sample and for each individual in particular [Veenema et al., 1994): CCT $=(\mathrm{a}-\mathrm{d}) / \mathrm{t}$, wherein a is the number of attracted pairs, $\mathrm{d}$ is the number of dispersed pairs, and $t$ is the total number of PC-MC pairs. Only PC-MC pairs formed by the subject responsible for initiating the conflict (hereafter aggressor) and the victim were considered.

Next, using the log-survival non-parametric Mantel-Cox test, we compared the temporal distribution of first affiliative contacts during PCs and MCs. Since no significant differences were found between distributions (see Results), reconciled conflicts were defined as those in which an attracted pair occurred. To test whether the type of first affiliative contact differed between PCs and MCs, we ran a generalized linear mixed model (GLMM) with the type of affiliative behaviour (implicit: proximity-sit; explicit: affiliative signals, sexual behaviour, contact-sit, play and grooming) as a dependent variable and the observation type (PC, MC) as independent variable.

GLMMs were also used to understand which variables affect the occurrence of reconciliation. These variables were related to opponents' demographic characteristics, type and context of the conflict and opponents' social relationship (table 1).

Individual dominance ranks were assessed via David's score [David 1987, 1988], with the correction proposed by de Vries et al. [2006]. When constructing dominance matrices, polyadic conflicts were broken down into dyadic components. An index of counter-intervention was calculated by dividing the number of conflicts in which A supported B's opponent, or B supported A's opponent, divided by the total number of conflicts involving A or B, excluding those in which A and B were opponents. A similar index was calculated for support. For dominance ranks, counter-intervention and support, besides the 190 conflicts for which we had valid PCMC pairs we used data from 24 additional conflicts (total =214) for which we did not have complete PC-MC pairs. Following Verbeek and de Waal [1997], conflicts occurring <90 min after the introduction of food trays were considered as belonging to 'food' context. Retaliation (i.e. aggression between opponents observed during PCs) and redirection (i.e. victim observed to direct aggression to third parties during PCs) events were considered only if they occurred before affiliation of former opponents. Social relationship variables, together with dominance ranks, were computed separately for 2004 and 2005 data. Social variables were assigned to the different dimensions of relationship quality according to Fraser et al. [2008] and Majolo et al. [2009]. Both studies use grooming reciprocation as an indicator of relationship security. Given that more than $40 \%$ (78 out of 190) of the conflicts were between opponents who did not groom each other, we removed grooming reciprocity from the analyses and did not test the possible effect of relationship security on reconciliation.

The best GLMM was chosen by using a step-up strategy whereby fixed factors with the lowest Akaike information criterion value were added sequentially to the model.

To determine whether conflicts lead to increased postconflict stress levels, individual rates of SDBs for each minute of the PC, where neither affiliative behaviour between former opponents occurred nor the victim was involved in episodes of renewed aggression (either with previous opponents - 26 conflicts - or third parties), were compared to MC rates using linear mixed models (LMMs; $n=100$ ). Given that victims became aroused only in the first 3 min after a conflict (see Results), this time window was too short for us to test whether affiliation reduced postconflict anxiety. As such, we explored only the factors affecting SDB rate in the first $3 \mathrm{~min}$ after conflicts, calculated as the difference between the average of the first $3 \mathrm{~min}$ of the PC and the corresponding MC individual average. Only PC observations where no affiliative contact between former opponents or renewed aggression was observed in the first 3 min were included $(n=130)$. To build the LMM, we followed the same step-up strategy and used the independent variables described previously for the reconciliation GLMM, plus victims' baseline SDB rates (measured in the corresponding MCs).

GLMMs were run in R version 2.7.2 using lmer function [Bates and Sarkar, 2008]. Victim and aggressor identity were inserted as random effects to avoid pseudoreplication. 
Table 1. Description of the variables considered that can potentially affect the occurrence of reconciliation

\begin{tabular}{|c|c|}
\hline Name & Type and description \\
\hline \multicolumn{2}{|l|}{ Dependent variable } \\
\hline Reconciliation & dichotomous $(0=$ no, $1=$ reconciliation $)$ \\
\hline \multicolumn{2}{|l|}{ Fixed explanatory variables } \\
\hline \multicolumn{2}{|l|}{ Demographic variables } \\
\hline Sex of aggressor & dichotomous $(0=$ male, $1=$ female $)$ \\
\hline Sex of victim & dichotomous $(0=$ male, $1=$ female $)$ \\
\hline Sex of opponents & $\begin{array}{l}\text { categorical }(0=\text { male-male, } 1=\text { male-female, } \\
2=\text { female-female })\end{array}$ \\
\hline Age of aggressor & dichotomous $(0=$ immature, $1=$ adult $)$ \\
\hline Age of victim & dichotomous $(0=$ immature, $1=$ adult $)$ \\
\hline Age of opponents & $\begin{array}{l}\text { categorical }(0=\text { immature-immature, } \\
1=\text { immature-adult, } 2=\text { adult-adult })\end{array}$ \\
\hline Rank of aggressor & continuous (David's score) \\
\hline Rank of victim & continuous (David’s score) \\
\hline Rank of aggressor-victim & continuous (David's score) \\
\hline \multicolumn{2}{|l|}{ Context and type of conflict variables } \\
\hline Context & dichotomous $(0=$ no-food, 1 = food $)$ \\
\hline Intensity & $\operatorname{dichotomous}(0=$ threat, $1=$ physical aggression $)$ \\
\hline Result & dichotomous $(0=$ undecided, $1=$ decided $)$ \\
\hline Number of opponents involved & dichotomous $(0=$ dyadic, $1=$ polyadic $)$ \\
\hline Retaliation & dichotomous $(0=$ no, $1=$ retaliation $)$ \\
\hline Redirection & dichotomous $(0=$ no, $1=$ redirection $)$ \\
\hline \multicolumn{2}{|l|}{ Social relationship variables } \\
\hline \multicolumn{2}{|l|}{ Value } \\
\hline Grooming given aggressor-victim & continuous $(\mathrm{min} / \mathrm{h})$ \\
\hline Grooming given victim-aggressor & continuous $(\mathrm{min} / \mathrm{h})$ \\
\hline Grooming dyad & continuous $(\mathrm{min} / \mathrm{h})$ \\
\hline Proximity & continuous (\% of samples within $1 \mathrm{~m}$ ) \\
\hline Support & $\begin{array}{l}\text { continuous (frequency of support/ } \\
\text { opportunity to support) }\end{array}$ \\
\hline \multicolumn{2}{|r|}{ opporturity (o support) } \\
\hline Counter-intervention & $\begin{array}{l}\text { continuous (frequency of intervention/opportunity } \\
\text { to intervene) }\end{array}$ \\
\hline Aggression & frequency of conflicts \\
\hline \multicolumn{2}{|l|}{ Random variable } \\
\hline Victim & nominal \\
\hline Aggressor & nominal \\
\hline
\end{tabular}

\section{Results}

The total number of PC-MC pairs recorded was 190 from 14 individuals (mean $\pm \mathrm{SD}=13.6 \pm 14.1$ ). Overall, reconciliation (i.e. number of attracted PC-MC pairs) was observed after $26.8 \%$ of conflicts (51 attracted, 33 dispersed and 106 neutral; $\mathrm{CCT}=0.111)$. The mean individual CCT $\pm \mathrm{SD}$ was $0.126 \pm 0.307$. 


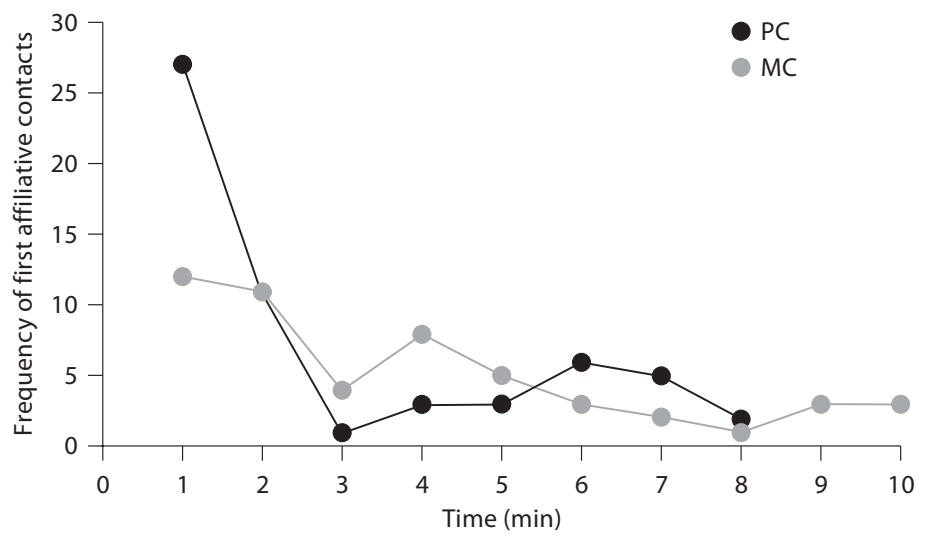

Fig. 1. Temporal distribution of first affiliative interaction between former opponents during PCs and MCs.

Table 2. GLMM comparing the occurrence of explicit first affiliative contacts in postconflict and matched-control periods

\begin{tabular}{|c|c|c|c|c|}
\hline \multicolumn{3}{|l|}{ Fixed factor } & \multicolumn{2}{|l|}{ Random factors } \\
\hline estimate $\pm \mathrm{SE}$ & $\mathrm{z}$ & $\mathrm{p}$ & victim identity & aggressor identity \\
\hline $1.66 \pm 0.48$ & 3.47 & $<0.001$ & variance $<0.001$ & variance $=0.407$ \\
\hline
\end{tabular}

Estimate represents the difference between PCs and MCs. Residual variance for random variables is not available for GLMMs.

Log survival analysis showed that the temporal distribution of first affiliative interactions between former opponents in the PCs was not significantly different from that in the MCs (Mantel-Cox test: $\log$ rank = 1.264; d.f. $=1 ; \mathrm{p}=0.261$; fig. 1). The types of first affiliative contact compared as follows: proximity-sit, $\mathrm{PC}=54.1 \%$, $\mathrm{MC}=84.6 \%$; affiliative signals, $\mathrm{PC}=24.6 \%, \mathrm{MC}=7.7 \%$; sexual behaviour, $\mathrm{PC}=9.8 \%$, $\mathrm{MC}=0.0 \%$; contact-sit, $\mathrm{PC}=6.6 \%, \mathrm{MC}=3.8 \%$; play, $\mathrm{PC}=3.3 \%, \mathrm{MC}=3.8 \%$; grooming, $\mathrm{PC}=1.6 \%, \mathrm{MC}=0.0 \%$. Affiliative contacts consisting of simple proximity sitting were more frequent in MC periods (table 2). Victims were responsible for initiating most of these interactions both in PC (41 out of 61-67.2\%) and MC periods (40 out of $52-76.9 \%)$.

We analysed the occurrence of reconciliation using GLMMs, following the procedure described above. The best model (lowest Akaike information criterion) comprised proximity, age of the aggressor, support and the result of conflict (table 3). Reconciliation was more likely to occur when the aggressor was an immature indi- 


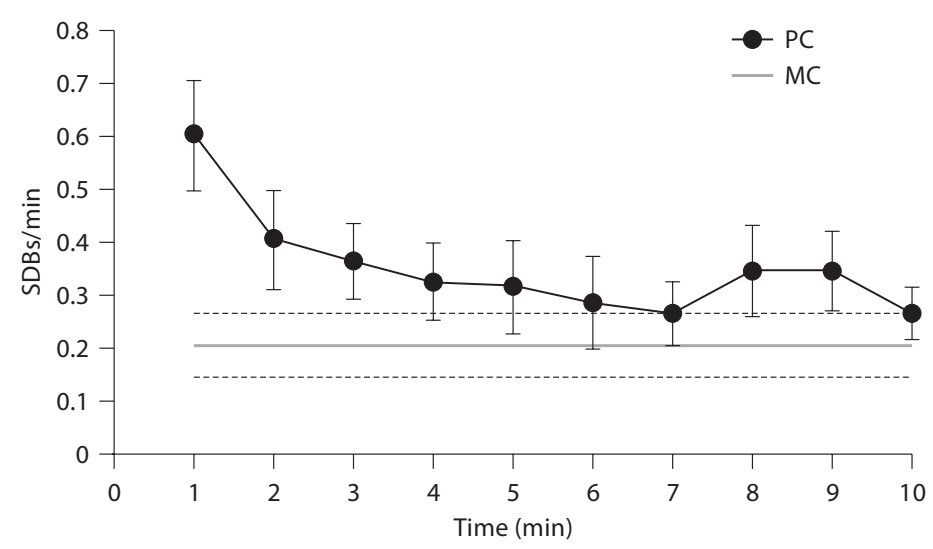

Fig. 2. SDB rates (scratching + self-grooming + body-shaking) per minute during PCs without affiliation between former opponents and postconflict aggression and MCs. PC distribution is the mean for each minute $( \pm \mathrm{SE})$, and MC distribution is the mean and the $95 \%$ confidence interval over the whole 10 -min sample.

Table 3. Variables included in the best GLMM on the occurrence of reconciliation (fixed factors are presented according to the order in which they were entered in the model)

\begin{tabular}{lccc}
\hline Variables & Estimate $\pm \mathrm{SE}$ & $\mathrm{z}$ & $\mathrm{p}$ \\
\hline Fixed factors & & & \\
$\quad$ Proximity & $4.67 \pm 2.51$ & 1.86 & 0.063 \\
$\quad$ Age of aggressor immature & $2.01 \pm 0.81$ & 2.46 & 0.014 \\
$\quad$ Support & $22.93 \pm 9.32$ & 2.46 & 0.014 \\
$\quad$ Result of conflict undecided & $1.73 \pm 0.94$ & 1.84 & 0.066 \\
Random factor & & \\
$\quad$ Victim identity & variance $<0.001$ & & \\
$\quad$ Aggressor identity & variance $=0.159$ & & \\
\hline
\end{tabular}

For dichotomous variables only one level is presented since the estimate represents the difference between the two levels. Residual variance for random variables is not available for GLMMs.

vidual and when the conflict was between opponents that supported each other more frequently. Time spent in close proximity and undecided conflicts had a positive and near significant effect on reconciliation.

In PC periods where neither affiliative behaviour between former opponents occurred nor was the victim involved in episodes of renewed aggression, victims showed an increased rate of scratching (fig. 2). Such an increase was limited to the 
Table 4. LMMs showing the effects of observation type (postconflict periods without affiliation between former opponents or postconflict aggression and MCs) on levels of SDB

\begin{tabular}{llllllll}
\hline & \multicolumn{3}{l}{ Fixed factor } & \multicolumn{5}{l}{ Random factor } \\
\cline { 2 - 3 } \cline { 7 - 8 } & estimate $\pm \mathrm{SE}$ & $\mathrm{t}$ & $\mathrm{p}$ & & $\begin{array}{l}\text { victim identity } \\
\text { variance }\end{array}$ & $\begin{array}{l}\text { aggressor identity } \\
\text { variance }\end{array}$ & $\begin{array}{l}\text { residual } \\
\text { variance }\end{array}$ \\
\hline 1st min & $0.39 \pm 0.08$ & 4.86 & $<0.001$ & & $<0.001$ & $<0.001$ & 0.432 \\
2nd min & $0.18 \pm 0.07$ & 2.46 & 0.015 & & 0.006 & $<0.001$ & 0.363 \\
3rd min & $0.14 \pm 0.06$ & 2.27 & 0.024 & & $<0.001$ & $<0.001$ & 0.232 \\
\hline
\end{tabular}

Estimate represents the difference between each PC minute and MC average. For brevity we present test results only for the minutes in which we found significant differences.

Table 5. Factors influencing postconflict scratching shown by victims of aggression (fixed factors are presented according to the order in which they were entered in the model)

\begin{tabular}{lcrl}
\hline Variables & Estimate $\pm \mathrm{SE}$ & $\mathrm{t}$ & $\mathrm{p}$ \\
\hline Fixed factors & & & \\
$\quad$ Grooming dyad & $-2.55 \pm 21.94$ & -0.12 & 0.908 \\
$\quad$ Support & $-5.15 \pm 4.23$ & -1.22 & 0.226 \\
$\quad$ Counter-intervention & $-1.15 \pm 4.22$ & 0.75 & 0.458 \\
$\quad$ Baseline SDB & $-0.30 \pm 0.12$ & -1.61 & 0.119 \\
Intensity weak aggression & $0.83 \pm 1.24$ & -0.67 & 0.013 \\
$\quad$ Proximity & & & \\
Random factors & variance $=0.020$ & & \\
$\quad$ Victim identity & variance $=0.014$ & & \\
Aggressor identity & variance $=0.353$ & & \\
$\quad$ Residual & &
\end{tabular}

For dichotomous variables only one level is presented since the estimate represents the difference between the two levels.

first 3 min after aggression (table 4). The best LMM, with the difference between the average scratching rate in the first 3 min of PCs and MC rates as a dependent variable, included 6 fixed factors (table 5). Only conflict intensity had a significant positive effect on PC SDB rates. Conflicts involving physical aggression increased SDBs more than conflicts involving only threats. The step-up strategy of sequentially adding fixed factors to the LMM created a model where the first 3 factors were grooming given to aggressor by victim, grooming given to victim by aggressor and dyadic grooming. Since these variables are highly correlated with each other, we chose to include in the model only the total amount of grooming exchanged by each dyad. 


\section{Discussion}

Reconciliation, defined as the occurrence of an attracted pair, occurred in approximately a quarter $(26.8 \%)$ of captive brown capuchin conflicts. The mean CCT (0.126) is on the lower end of the scale for primate studies [Arnold and Aureli, 2007]. The temporal distributions of first affiliative interactions between former opponents did not differ significantly between PCs and MCs, although most postconflict interactions occurred in the first $2 \mathrm{~min}$ and involved more intense first affiliative contacts than in matched-control periods (i.e. less simple sitting in close proximity and more affiliative signals, physical contact, play, grooming and sexual behaviour).

Reconciliation was more frequent following conflicts between capuchins that supported each other frequently when the aggressor was an immature individual and, to a lesser extent, when conflicts had an undecided outcome and occurred between opponents that spent more time in proximity. Given that frequency of agonistic support and time spent in proximity are associated with relationship value [Fraser et al., 2008], our results provide support for the valuable relationship hypothesis [de Waal and Aureli, 1997]. Grooming is generally related to relationship value but we did not find that it influenced reconciliation. Available grooming data on brown capuchins are highly inconsistent, with some authors suggesting that C. apella groom down the hierarchy [di Bitetti, 1997; Parr et al., 1997], while others have found no relation between grooming and rank [Schino et al., 2009a]. Evidence of exchange of grooming for support is also contradictory [di Bitetti, 1997; Schino et al., 2009a]. Despite the increasing number of studies on capuchins' behaviour, the role of grooming in their social life is still puzzling.

Among the variables measuring social relationships, two of them (index of counter-intervention and frequency of aggression) relate to relationship compatibility, none of which influenced reconciliation. These results are in agreement with the idea that the value of a relationship is the most important determinant of conflict resolution, while compatibility and security play a less relevant role [Majolo et al., 2009]. Despite recent efforts to group different measures of social interactions into the three dimensions of relationship quality [Fraser et al., 2008], further studies are needed to examine the consistency of these results in other species.

Non-adult aggressors reconciled a higher proportion of their conflicts. Most coalitionary support in brown capuchin monkeys has been described as protective interventions (often by the alpha male) involving immatures [Ferreira et al., 2006]. Reconciling a conflict with an immature may be a way to prevent the intervention of a higher-ranking adult. Although we observed a reduced number of interventions (36), the pattern of Ferreira et al. [2006] does not match our data. In our sample immatures were the most active supporters and not the recipients of support. The role of the aggressor's age should be interpreted cautiously, since immature individuals were responsible for initiating only 10 of the 190 conflicts.

Conflicts with no clear signs of submission were reconciled more often than decided conflicts. Uncertainty associated with undecided conflicts may increase the opponents' motivation to reconcile [Aureli et al., 1989]. Again, the reduced number of undecided conflicts recorded (6) prevents us from more conclusive statements.

Contrary to previous findings on capuchins [Verbeek and de Waal, 1997], food context had no significant effect on reconciliation. Also, postconflict anxiety did not 
differ between conflicts in both contexts. Most studies that have compared the occurrence of reconciliation in feeding and non-feeding contexts have found that reconciliation occurs less often in food-related conflicts [Arnold and Aureli, 2007]. However, there are a few studies where reconciliation was not affected by the feeding context [Arnold and Whiten, 2001; Cooper and Bernstein, 2002; Wittig and Boesch, 2003].

Initial affiliative interactions between aggressors and victims frequently consisted of sitting in close proximity, without the exchange of more obvious affiliative displays. The use of close proximity as an indicator of a conciliatory tendency raises some comparability questions with many studies. Even so, spatial adjustment is determined by past interactions and influences future behavioural events [Fairbanks, 1976], supporting its use as a form of implicit reconciliation [York and Rowell, 1988; Cords, 1993; Verbeek and de Waal, 1997; Pereira et al., 2000]. Species with low rates of reconciliation rarely use explicit contacts to reconcile, and the specific repertoire of affiliative behaviours should be taken into account since the same behaviour may not serve the same function in different species [Aureli et al., 2002; Arnold and Aureli, 2007; Thierry et al., 2008].

Comparison of macaque species revealed that postconflict behaviour is clearly constrained by the type of dominance relationships, with despotic species exhibiting higher conciliatory tendencies than more egalitarian ones [Thierry et al., 2008]. Cebus species also display great variability in social characteristics providing a great opportunity for comparative studies [Fragaszy et al., 2004]. Higher conciliatory tendencies in white-faced capuchins [Leca et al., 2002; Manson et al., 2005] may be a reflection of a less asymmetrical dominance style than that of brown capuchin monkeys. White-faced capuchins have more polyadic conflicts with most interventions being directed against the aggressor [Leca et al., 2002], while we found third-party intervention to be less frequent and favouring the aggressor. Renewed aggression also occurred more often in C. capucinus conflicts [Manson et al., 2005]. In whitefaced capuchins, aggressors were at least equally likely of initiating postconflict affiliation [Leca et al., 2002; Manson et al., 2005], contrary to what we have shown in brown capuchins, where victims initiated most postconflict friendly interactions with former opponents.

Victims of conflicts showed a stress response in the aftermath of agonistic encounters, indexed by elevated rates of SDBs, even though conflicts rarely re-flared. Of all the variables studied, only conflict intensity had a significant effect on postconflict anxiety. Arousal was more pronounced following conflicts that involved physical aggression instead of simple threats. Disruption of a valuable relationship has been hypothesized as one of the main causes of postconflict anxiety [Aureli, 1997; Kutsukake and Castles, 2001; Cooper et al., 2007; Koski et al., 2007]. Our results do not support this hypothesis, since none of the variables thought to measure relationship quality had a significant effect on postconflict stress. Similar findings have also been reported for Japanese macaques, Macaca fuscata [Schino et al., 2007].

Based on the low conciliatory tendency observed, if reconciliation is a fundamental mechanism to maintain brown capuchins' group coherence, reconciliating a small proportion of conflicts may be sufficient to prevent degradation of social relationships, or instead, it is possible that only conflicts perceived as threatening need to be reconciled [Aureli et al., 2002; Schino et al., 2007; Silk, 2007]. On the other 
hand, reconciliation may not be necessary to maintain brown capuchins' group coherence, since it occurs at a low rate and postconflict anxiety rapidly decreases even in its absence. Extending reconciliation research to other Cebus species should be a priority for further studies.

\section{Acknowledgments}

Special thanks go to Paulo Figueiras for permission to conduct this study at the Zoo de Lagos, Portugal. We would also like to acknowledge Brian Vaughn and anonymous reviewers for valuable comments on previous versions of the manuscript. This study was funded by the Centro de Investigação e Intervenção, Instituto Superior de Psicologia Aplicada.

\section{References}

Arnold K, Aureli F (2007). Postconflict reconciliation. In Primates in Perspective (Campbell CJ, Fuentes A, MacKinnon KC, Panger M, Bearder SK, eds.), pp 592-608. New York, Oxford University Press.

-Arnold K, Whiten A (2001). Post-conflict behaviour of wild chimpanzees (Pan troglodytes schweinfurthii) in the Budongo Forest, Uganda. Behaviour 138: 649-690.

-Aureli F (1992). Post-conflict behavior among wild long-tailed macaques (Macaca fascicularis). Behavioral Ecology and Sociobiology 31: 329-337.

-Aureli F (1997). Post-conflict anxiety in nonhuman primates: the mediating role of emotion in conflict resolution. Aggressive Behavior 23: 315-328.

Aureli F, de Waal FBM (2000). Natural Conflict Resolution. Berkeley, University of California Press.

- Aureli F, van Schaik CP (1991). Post-conflict behavior in long-tailed macaques (Macaca fascicularis). II. Coping with the uncertainty. Ethology 89: 101-114.

- Aureli F, Cords M, van Schaik CP (2002). Conflict resolution following aggression in gregarious animals: a predictive framework. Animal Behaviour 64: 325-343.

- Aureli F, van Schaik CP, van Hooff JARAM (1989). Functional aspects of reconciliation among captive long-tailed macaques (Macaca fascicularis). American Journal of Primatology 19: 39-51.

Bates D, Sarkar D (2008). lme4: linear mixed-effects models Using S4 classes, R package version 0.999375-27.

-Castles DL, Whiten A (1998). Post-conflict behaviour of wild olive baboons. II. Stress and self-directed behaviour. Ethology 104: 148-160.

-Cooper MA, Bernstein IS (2002). Counter aggression and reconciliation in Assamese macaques (Macaca assamensis). American Journal of Primatology 56: 215-230.

-Cooper MA, Aureli F, Singh M (2007). Sex differences in reconciliation and post-conflict anxiety in bonnet macaques. Ethology 113: 26-38.

Cords M (1993). On operationally defining reconciliation. American Journal of Primatology 29: 255267.

Cords M, Aureli F (2000). Reconciliation and relationship qualities. In Natural Conflict Resolution (Aureli F, de Waal FBM, eds.), pp 177-198. Berkeley, University of California Press.

Das M, Penke Z, van Hooff JARAM (1998). Postconflict affiliation and stress-related behavior of longtailed macaque aggressors. International Journal of Primatology 19: 53-71.

David HA (1987). Ranking from unbalanced paired-comparison data. Biometrika 74: 432-436.

David HA (1988). The Method of Paired Comparisons. London, Griffin.

de Vries H, Stevens JMG, Vervaecke H (2006). Measuring and testing steepness of dominance hierarchies. Animal Behaviour 71: 585-592.

de Waal FBM, Aureli F (1997). Conflict resolution and distress alleviation in monkeys and apes. In The Integrative Neurobiology of Affiliation (Carter CS, Lenderhendler II, Kirkpatrick B, eds.), pp 317328. New York, Annals of the New York Academy of Sciences.

-de Waal FBM, Yoshihara D (1983). Reconciliation and redirected affection in rhesus monkeys. Behaviour 85 : 224-241.

di Bitetti MS (1997). Evidence for an important social role of allogrooming in a platyrrhine primate. Animal Behaviour 54: 199-211. 
Fairbanks L (1976). A comparative analysis of subgroup structure and spatial relationships in captive baboons and squirrel monkeys. Primates 17: 291-300.

Ferreira RG, Izar P, Lee PC (2006). Exchange, affiliation, and protective interventions in semifree-ranging brown capuchin monkeys (Cebus apella). American Journal of Primatology 68: 765-776.

Fragaszy DM, Visalberghi E, Fedigan L (2004). The Complete Capuchin. Cambridge, Cambridge University Press.

Fraser ON, Schino G, Aureli F (2008). Components of relationship quality in chimpanzees. Ethology 114: 834-843.

Groves CP (2001). Primate Taxonomy. Washington, Smithsonian Institution Press.

Izar, P (1994). Análise da estrutura social de um grupo de macacos-prego (Cebus apella) em condições de semi-cativeiro. Master's thesis, Universidade de São Paulo.

Koski SE, Koops K, Sterck EHM (2007). Reconciliation, relationship quality, and postconflict anxiety: testing the integrated hypothesis in captive chimpanzees. American Journal of Primatology 69: $158-172$.

Kutsukake N, Castles DL (2001). Reconciliation and variation in post-conflict stress in Japanese macaques (Macaca fuscata fuscata): testing the integrated hypothesis. Animal Cognition 4: 259268.

Leca JB, Fornasieri I, Petit O (2002). Aggression and reconciliation in Cebus capucinus. International Journal of Primatology 23: 979-998.

Maestripieri D, Schino G, Aureli F, Troisi A (1992). A modest proposal: displacement activities as an indicator of emotions in primates. Animal Behaviour 44: 967-979.

Majolo B, Ventura R, Koyama NF (2009). A statistical modelling approach to the occurrence and timing of reconciliation in wild Japanese macaques. Ethology 115: 152-166.

Manson JH, Perry S (2000). Correlates of self-directed behavior in wild white-faced capuchins. Ethology 106: 301-317.

Manson JH, Perry S, Stahl D (2005). Reconciliation in wild white-faced capuchins (Cebus capucinus). American Journal of Primatology 65: 205-219.

Parr LA, Matheson MD, Bernstein IS, de Waal FBM (1997). Grooming down the hierarchy: allogrooming in captive brown capuchin monkeys, Cebus apella. Animal Behaviour 54: 361-367.

Pereira ME, Schill JL, Charles EP (2000). Reconciliation in captive Guyanese squirrel monkeys (Saimir sciureus). American Journal of Primatology 50: 159-167.

Romero T, Colmenares F, Aureli F (2009). Testing the function of reconciliation and third-party affiliation for aggressors in hamadryas baboons (Papio hamadryas hamadryas). American Journal of Primatology 71: 60-69.

Rylands AB, Schneider H, Langguth A, Mittermeier RA (2000). An assessment of the diversity of New World primates. Neotropical Primates 8: 61-93.

-Schino G, di Giuseppe F, Visalberghi E (2009a). Grooming, rank, and agonistic support in tufted capuchin monkeys. American Journal of Primatology 71: 101-105.

-Schino G, di Giuseppe F, Visalberghi E (2009b). The time frame of partner choice in the grooming reciprocation of Cebus apella. Ethology 115: 70-76.

Schino G, Rosati L, Geminiani S, Aureli F (2007). Post-conflict anxiety in Japanese macaques (Macaca fuscata): aggressor's and victim's perspectives. Ethology 113: 1081-1088.

Schino G, Scucchi S, Maestripieri D, Turillazzi PG (1988). Allogrooming as a tension-reduction mechanism: a behavioral approach. American Journal of Primatology 16: 43-50.

Silk JB (2007). Animal behavior: conflict management is for the birds. Current Biology 17: R50-R51.

Thierry B, Aureli F, Nunn CL, Petit O, Abegg C, de Waal FBM (2008). A comparative study of conflict resolution in macaques: insights into the nature of trait covariation. Animal Behaviour 75: 847860.

Veenema HC, Das M, Aureli F (1994). Methodological improvements for the study of reconciliation. Behavioral Processes 31: 29-37.

Verbeek P, de Waal FBM (1997). Postconflict behavior of captive brown capuchins in the presence and absence of attractive food. International Journal of Primatology 18:703-725.

Watts D (2006). Conflict resolution in chimpanzees and the valuable-relationships hypothesis. International Journal of Primatology 27: 1337-1364.

-Weaver A, de Waal FBM (2003). The mother-offspring relationship as a template in social development: reconciliation in captive brown capuchins (Cebus apella). Journal of Comparative Psychology 117: $101-110$.

Wittig RM, Boesch C (2003). The choice of post-conflict interactions in wild chimpanzees (Pan troglodytes). Behaviour 140: 1527-1559.

York AD, Rowell TE (1988). Reconciliation following aggression in patas monkeys, Erythrocebus patas. Animal Behaviour 36: 502-509. 